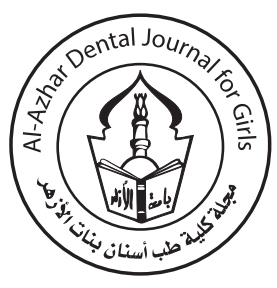

\title{
The Effect of Different Bar Materials on Stress Distribution in Implant Supported Mandibular Overdenture Supporting Structure. (An in-Vitro Study)
}

\author{
Ehab M. Abd-Elhaleim ${ }^{(1)}$, Maged G. Al-Sadaawey ${ }^{(1)}$ and Reda A. Ragab ${ }^{(1)}$
}

Codex : 12/1801

azhardentj@azhar.edu.eg

http://adjg.journals.ekb.eg

\section{KEYWORDS}

Bar Materials,

Stress Distribution,

Implant, Overdenture

\begin{abstract}
Objective: To study the effect of different bar materials (cobalt chromium \& polyetheretherketone) on stress distribution in implant supported mandibular overdenture supporting structure .By using strain gauge analysis. Material and methods: Six bar attachments were made from different materials (cobalt chromium\& polyetheretherketone) and were constructed in acrylic model for implant supported mandibular overdenture and determine stress distribution in implant and supporting structure by using strain gauge analysis. Results: Showing No statistically significant difference was found between ( $\mathrm{CoCr}$ ) bars and (PEEK) bars on stress distribution in implant supported mandibular overdenture supporting structure when Comparison between recorded microstrains measured with unilateral and bilateral load application. Conclusion: The cobalt chromium bars are subjected to more stresses than polyetheretherketone. Significantly greater amount of stresses are transmitted to the implants whether unilateral or bilateral in all loading situations. Unilateral loading is more traumatic to the implants and residual ridge compared to bilateral loading.
\end{abstract}

\section{INTRODUCTION}

Overdenture is any removable dental prosthesis that covers and rests on one or more remaining natural teeth, roots of natural teeth and/or dental implants ${ }^{(1)}$. Overdentures provide a better function than conventional complete dentures through a variety of factors, such as improved biting force, chewing efficiency and increased speed of controlled mandibular movement ${ }^{(2)}$.

In addition, they minimize the downward and forward settling of a denture, which otherwise occurs with alveolar bone resorption ${ }^{(3)}$. Therefore, two-implants supported overdenture in the mandible should be the standard treatment modality for full edentulous patients suffering from discomfort with their conventional denture ${ }^{(4,5)}$

1. Prosthodontics Dep., Faculty of dentistry, Al-azhar Univ., Assuit Branch. 
However, several articles showed that the nonsplinted design requires more prosthetic maintenance and the bar attachment system has been shown to be a more successful prosthesis ${ }^{(6)}$, While bar system has the best maintainability ${ }^{(7)}$.

Laboratory procedures such as soldering and welding give rise to errors and increase in cost. Besides, several bar framework material such as gold alloy, silver-palladium alloy, commercially pure titanium, and cobalt-chromium alloy presented a lower effect on the stress distribution of an overdenture ${ }^{(8)}$.

One way to evaluate the stress distribution around the implants "in vitro" studies is the use of strain gauge, which is a technique for the recording of microstrain through the alteration of the electrical resistance. The function of this circuit is to convert a resistance change to an electrical voltage which can therefore be measured with great accuracy at the place where the strain gauge is placed ${ }^{(9)}$. Recently, polyetheretherketone has been introduced into the field of prosthetic dentistry. Many applications such as dental implants, provisional abutments or clamps for removable dental prostheses ${ }^{(\mathbf{1 0}, 11,12)}$.

Furthermore, with a reported mean fracture load of $1383 \mathrm{~N}$ for three-unit fixed dental prostheses (FDPs), PEEK has also been considered as a suitable material, especially, for FDPs in load-bearing areas ${ }^{(13)}$.

\section{MATERIAL AND METHODS}

In this study six bar attachments from different materials (cobalt chromium \& polyetheretherketone) were used. Bar attachments were constructed in acrylic model.

\section{Acrylic model construction:}

An impression of an educational stone model was made using silicon impression material. Molten base plate wax was poured in to the silicon rubber impression using a mechanical vibrator and was left to be hardened. After complete hardening the cast in wax was removed. The cast in wax was processed in to pink heat cure acrylic model through flasking, wax elimination, packing and curing using long cycle, then left to bench cooling before finishing and polishing (Fig 1). Waxed up denture was made on the model for correct placement of the two implants in the canine regions.

\section{Implant insertion and preparation:}

Drilling was made in the canine regions and the implants were fixed parallel to each other in place using self cure acrylic resin.

\section{Bar attachment construction:}

Six mandibular overdentures supported by six bar attachments were constructed. The silicon rubber impression was made for the model after reduction of the two implants. The impression was poured in hard dental stone to produce six stone casts (Fig 2). Wax copings were constructed on the two implants. On the stone cast, the wax copings were connected with a bar. The wax pattern of the bar was polished with its rounded surface lightly contacting the ridge, and its flat surface facing occlusal. Spruing, investing, burn out and casting using cobalt-chromium alloy will performed for cobalt-chromium bars.

For polyetheretherketone bars: The initial situation is a wax model, which is invested in a mould with an investment material especially developed for this purpose. This mould is heated to between $630^{\circ} \mathrm{C}$ and $850^{\circ} \mathrm{C}$ in a pre-heating oven, the wax is melted away and then cooled at $400^{\circ} \mathrm{C}$. At this temperature, PEEK is brought to the melting range of this investment material mould and melted down. The insertion of the press plunger and transfer of the mould into the 2 press system then takes place. By for 2 press system then takes place. By for raising the lift, the pressing procedure is triggered automatically and takes place in a vacuum. After completion of the vacuum, the mould is cooled down to room temperature within 35 minutes - whilst maintaining the pressing pressure, Finishing and polishing of the polyetherertherketone bars. Cast coping interconnected with bars (co-cr and peek) and those were tried on the modified duplicated acrylic model to ensure their accurate fit on the implant abutments. 


\section{Construction of the overdentures:}

Rubber base impression was made for the model while the different bars removed and replaced to take different impression with the different bars and copings fitted to the implants. The Rubber base impressions were poured in hard dental stone to produce six stone casts. Posterior teeth were set with their buccal cusps centralized over the crest of the ridge and the height of the occlusal plane was set from the tip of the canine to the central of retomolar pad, for overdenture supported by cobalt-chromium bar. The position of the teeth and height of the occlusal plane was duplicated to the other studied using stone occlusal index constructed on a fixed condylar path articulator. Heat cure acrylic overdentures were constructed following the conventional technique (Fig 3). For picking up the clip attachment, a space was created in the fitting surface of the mandibular overdenture and vent holes were opened in the lingual flange opposite to the central bar. The clip was placed in its position on the bar. Undercuts beneath the bar were blocked out with sticky wax.

Auto-polymerizing acrylic resin was applied in the fitting surface of the denture opposite to the bar, and the overdenture was placed on the model. Firm steady pressure was applied on the overdentures bilaterally until complete curing of the resin take place.

\section{Installation of the strain gauges:}

Four strain gauges were used; two of them were installed in the distal side of two implants while the other two gauges were installed on the residual ridge of the first molar area. A fissure bur used to create groove $1 \mathrm{~mm}$ in the model to receive the strain gauge, at the first molar area of the model, after reduction of the ridge to simulate the mucosa and before application of the medium body rubber base, two grooves were created in the molar area of the edentulous ridge. Grooves were created on the buccal side of the ridge, below the crest of the ridge in a flat plane to measure the amount of load on the ridge. And At the distal aspect of the implant abutments where the strain gauges were to be installed, the axial wall below the crest of the ridge was reduced in flat plane parallel to the long axis of the implants. The reduced edentulous area was painted by separating medium. Medium body rubber base was placed in the overdenture, then it was repositioned and pressed in it is place tell completely seating guided by stoppers to produce an even thickness of medium body rubber base, even bilaterally seating pressure was applied until setting of impression material was completed.

\section{Load application and recording measurement:}

The first cobalt chromium straight bar was temporary cemented to the implant and the overdenture was fitted on the model and the bar. The acrylic model with the overdenture was ready to place on the lower metal plate of the universal testing machine (Fig. 4). The T-shaped load applicator of the universal testing machine was allowed to touch the denture teeth bilaterally at the central fosse of first molar (Fig.5). Simultaneous and even contacts between the bar and the artificial teeth on both sides at the previously mentioned positions were achieved by spot grinding guided using articulating paper markings. Load was applied using the universal testing machine at the central fosse of first molar bilaterally and unilaterally. The applied load started from zero up to $60 \mathrm{~N}$. The micro strains of the four strain gauges were recorded to measure the strains developed at the distal wall of the two implants and the residual ridge bellow the central fosse of the first molar for each load application. Once the load was completely applied, the micro strain readings were transferred to micro strain units from the four channel strain meter.

The same steps were followed with the other bars to measure the micro strains developed at the distal wall of the two implants and the residual ridge bellow the central fosse of the first molar. The obtained data was inspected, to detect the sudden drop of the measured micro strains. The mean of the last ten reading obtained from each channel before the incidence of the sudden drop of the measured micro strains were tabulated to compare between strains obtained from the six treatment modalities when bilaterally and unilaterally loaded. All data of the current study were collected and statistically analyzed. 


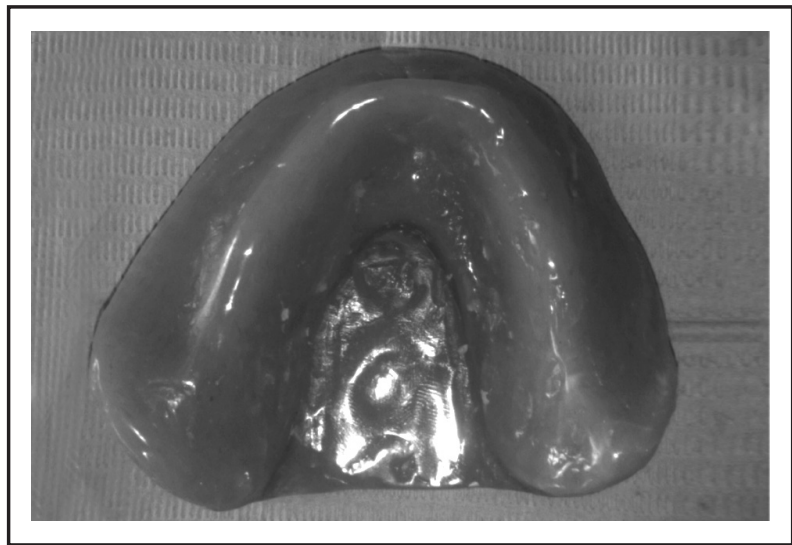

Fig. (1) Duplicated acrylic model.

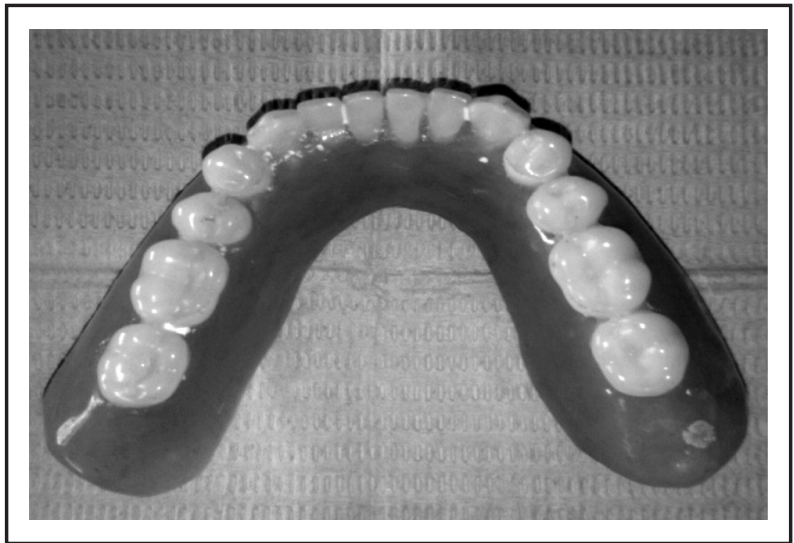

Fig. (3) Finished overednture.

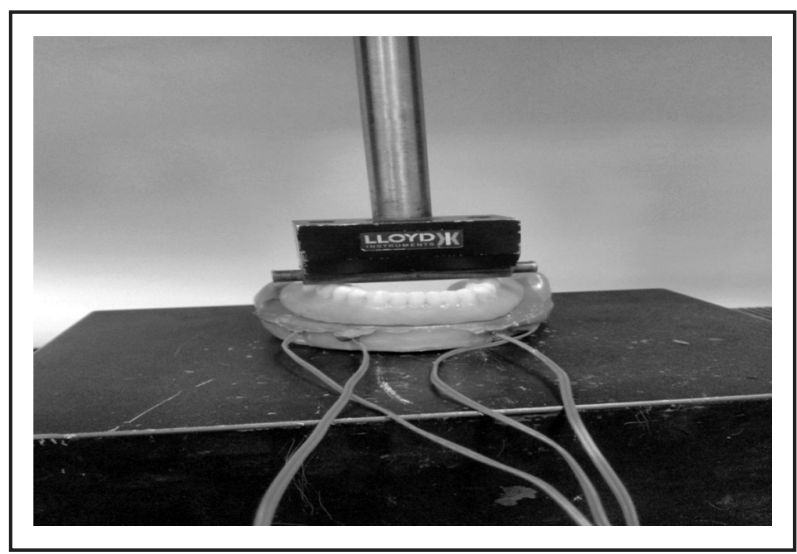

Fig. (5) Load application to the acrylic model.

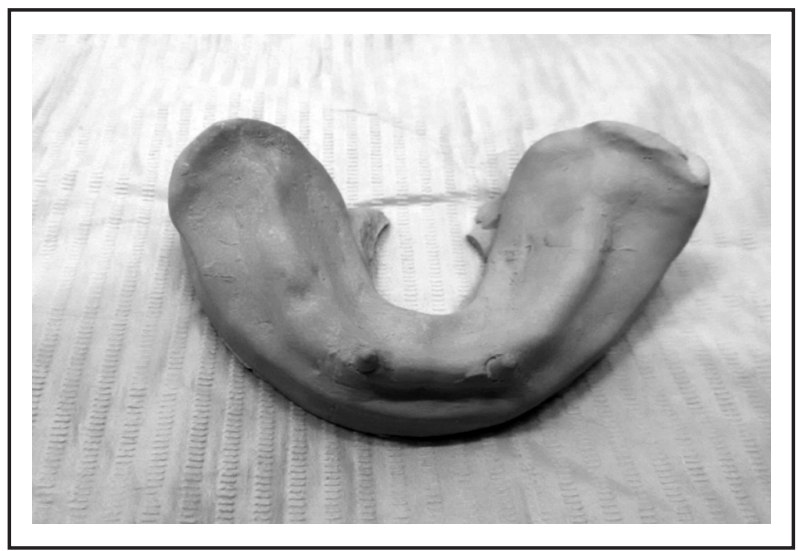

Fig. (2) Duplicated stone cast.

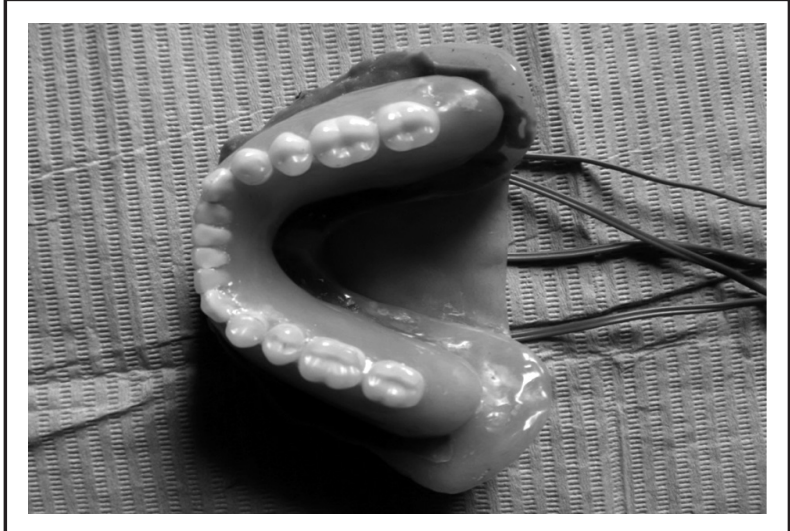

Fig. (4) Acrylic model with overdenture, strain gauge and simulating impression material.

\section{RESULTS}

The mean and standard deviation values were calculated for each group in each test. Data were explored for normality using Kolmogorov-Smirnov and Shapiro-Wilk tests and showed parametric (normal) distribution. The significance level was set at $\mathrm{P} \leq 0.05$. From Table (1) and (Fig. 6). It can be noticed that when Comparison between recorded microstrains measured with unilateral load application Microstrains induced on the implant that mean No statistically significant difference was found between $(\mathrm{CoCr})$ and (PEEK) For right side $(\mathrm{p}=0.074)$. and for left $\operatorname{side}(\mathrm{p}=0.222)$ Table(2) and(Fig.7). It can be noticed that when Comparison between recorded microstrains measured with Bilateral load application. Microstrains induced on the implant No statistically significant difference was found between $(\mathrm{CoCr})$ and $(\mathrm{PEEK})$ where $(\mathrm{p}=0.187)$ for 
right side while ( $\mathrm{p}=0.123$ )for left side. Microstrains induced on the ridge No statistically significant difference was found between $(\mathrm{CoCr})$ and (PEEK) where $(\mathrm{p}=0.447)$. for right side where $(\mathrm{p}=0.095)$ for left side. Microstrains induced on the ridge showed No statistically significant difference was found between $(\mathrm{CoCr})$ and (PEEK) where $(\mathrm{p}=0.093)$ For Right side while For Left side $(\mathrm{p}=0.117)$ Table (3) and (Fig. 8). It can be noticed that when Comparison between recorded microstrains measured with Unilateral and Bilateral load applicationin for CoCr. Microstrains induced on the implant: A statistically significant difference was found between (Unilateral) and (Bilateral) where $(\mathrm{p} \leq 0.001)$. for right side while for left side ( $\mathrm{p} \leq 0.001)$. Microstrains induced on the ridge (Molar area):

Table (1) The mean, standard deviation (SD) values of microstrains measured with unilateral load application. (Independent sample t-test)

\begin{tabular}{|c|c|c|c|c|c|c|}
\hline \multicolumn{6}{|c|}{ Unilateral load application } & \multirow{3}{*}{ P-value } \\
\hline \multirow{2}{*}{ Side } & \multirow{2}{*}{$\begin{array}{c}\text { Material } \\
\text { Site }\end{array}$} & \multicolumn{2}{|c|}{$\mathrm{CoCr}$} & \multicolumn{2}{|c|}{ PEEK } & \\
\hline & & Mean & SD & Mean & SD & \\
\hline \multirow{2}{*}{ Implant (Canine) } & Right & $34.30^{\mathrm{a}}$ & 3.81 & $29.50^{\mathrm{a}}$ & 3.56 & $0.074 \mathrm{~ns}$ \\
\hline & Left & $306.82^{a}$ & 16.47 & $300.60^{\mathrm{a}}$ & 18.26 & $0.222 \mathrm{~ns}$ \\
\hline \multirow{2}{*}{ Ridge (Molar) } & Right & $10.40^{\mathrm{a}}$ & 3.21 & $8.80^{\mathrm{a}}$ & 3.11 & $0.447 \mathrm{~ns}$ \\
\hline & Left & $14.60^{\mathrm{a}}$ & 4.16 & $9.80^{\mathrm{a}}$ & 3.85 & $0.095 \mathrm{~ns}$ \\
\hline
\end{tabular}

Table (2) The mean, standard deviation (SD) values of microstrains measured with Bilateral load application (Independent sample t-test)

\begin{tabular}{|c|c|c|c|c|c|c|}
\hline \multirow{2}{*}{ Side } & Material & \multicolumn{2}{|c|}{ CoCr } & \multicolumn{2}{c|}{ PEEK } & \multirow{2}{*}{ P-value } \\
\cline { 2 - 7 } & Site & Mean & SD & Mean & SD & \\
\hline \multirow{3}{*}{ Implant (Canine) } & Right & $298.60^{\mathrm{a}}$ & 18.09 & $288.10^{\mathrm{a}}$ & 14.13 & $0.187 \mathrm{~ns}$ \\
\cline { 2 - 8 } & Left & $380.00^{\mathrm{a}}$ & 16.22 & $373.50^{\mathrm{a}}$ & 15.68 & $0.123 \mathrm{~ns}$ \\
\hline \multirow{2}{*}{ Ridge (Molar) } & Right & $14.00^{\mathrm{a}}$ & 2.77 & $10.60^{\mathrm{a}}$ & 2.86 & $0.093 \mathrm{~ns}$ \\
\cline { 2 - 8 } & Left & $19.40^{\mathrm{a}}$ & 4.15 & $15.10^{\mathrm{a}}$ & 3.56 & $0.117 \mathrm{~ns}$ \\
\hline
\end{tabular}

Mean with different letters in the same row indicate statistically significance difference

*; significant $(p<0.05) \quad n s ;$ non-significant $(p>0.05)$

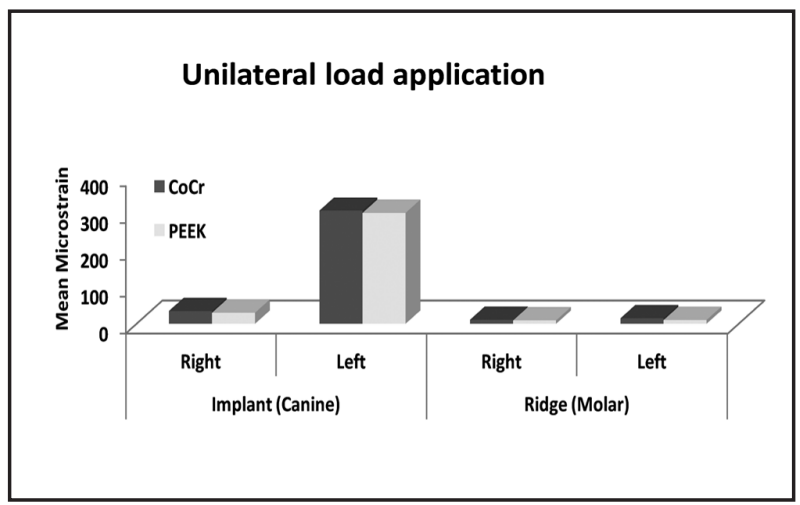

Fig. (6) Bar chart representing microstrains measured with unilateral load application.

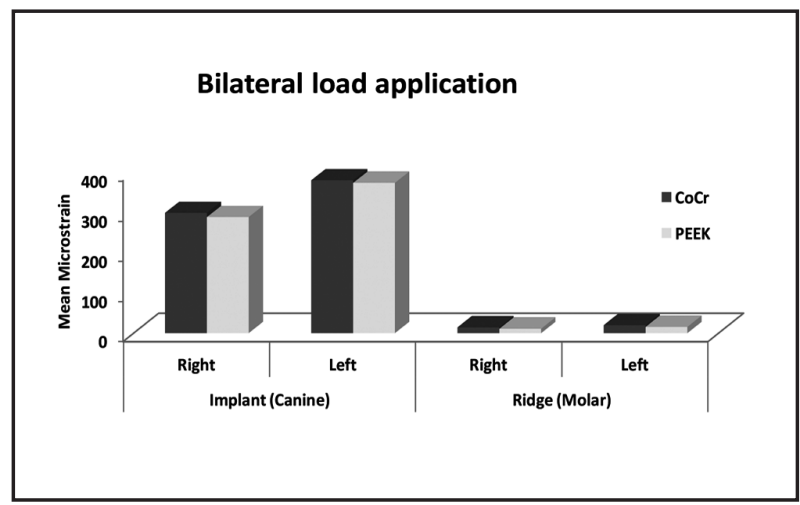

Fig. (7) Bar chart representing microstrains measured with bilateral load application. 
Table (3) The mean, standard deviation (SD) values of microstrains measured with Unilateral and Bilateral load application in $\mathrm{CoCr}$ (Paired t-test)

\begin{tabular}{|c|c|c|c|c|c|c|}
\hline \multirow{3}{*}{ Side } & Material & \multicolumn{2}{|c|}{ CoCr } & \multicolumn{2}{c|}{ Bilateral } & \multirow{2}{*}{ P-value } \\
\cline { 2 - 7 } & Site & Mean & SD & Mean & SD & \\
\hline \multirow{3}{*}{ Implant (Canine) } & Right & $34.30^{\mathrm{a}}$ & 3.81 & $298.60^{\mathrm{b}}$ & 18.09 & $\leq 0.001^{*}$ \\
\cline { 2 - 7 } & Left & $306.82^{\mathrm{a}}$ & 16.47 & $380.00^{\mathrm{b}}$ & 16.22 & $\leq 0.001^{*}$ \\
\hline \multirow{3}{*}{ Ridge (Molar) } & Right & $10.40^{\mathrm{a}}$ & 3.21 & $14.00^{\mathrm{a}}$ & 2.77 & $0.094 \mathrm{~ns}$ \\
\cline { 2 - 7 } & Left & $14.60^{\mathrm{a}}$ & 4.16 & $19.40^{\mathrm{a}}$ & 4.15 & $0.105 \mathrm{~ns}$ \\
\hline
\end{tabular}

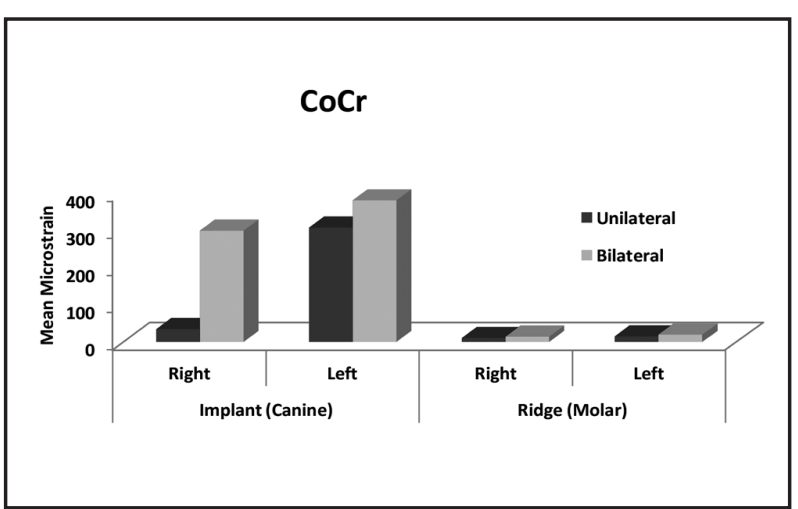

Fig. (8) Bar chart representing microstrains measured with Unilateral and Bilateral load application in $\mathrm{CoCr}$
No statistically significant difference was found between (Unilateral) and (Bilateral) where $(\mathrm{p}=0.094)$ For Right side while for left side $(\mathrm{p}=0.105)$ Table (4) and (Fig. 9). It can be noticed that when Comparison between recorded microstrains measured with Unilateral and Bilateral load application in for PEEK: Microstrains induced on the implant (Canine area): A statistically significant difference was found between (Unilateral) and (Bilateral) where $(\mathrm{p} \leq 0.001)$. For Right side: while For Left side $(\mathrm{p} \leq 0.001)$ Table(5) and (Fig.10). Microstrains induced on the ridge. No statistically significant difference was found between (Unilateral) and (Bilateral) where $(\mathrm{p}=0.369)$. For Right side: while For Left side $(\mathrm{p}=0.054)$.

Table (4) The mean, standard deviation (SD) values of microstrains measured with Unilateral and Bilateral load application n PEEK (Paired t-test).

\begin{tabular}{|c|c|c|c|c|c|c|}
\hline \multicolumn{6}{|c|}{ PEEK } & \multirow{3}{*}{ P-value } \\
\hline \multirow{2}{*}{ Side } & \multirow{2}{*}{$\begin{array}{c}\text { Material } \\
\text { Site }\end{array}$} & \multicolumn{2}{|c|}{ Unilateral } & \multicolumn{2}{|c|}{ Bilateral } & \\
\hline & & Mean & SD & Mean & SD & \\
\hline \multirow{2}{*}{ Implant (Canine) } & Right & $29.50^{\mathrm{a}}$ & 3.56 & $288.10^{\mathrm{b}}$ & 14.13 & $\leq 0.001 *$ \\
\hline & Left & $300.60^{\mathrm{a}}$ & 18.26 & $373.50^{b}$ & 15.68 & $\leq 0.001 *$ \\
\hline \multirow{2}{*}{ Ridge (Molar) } & Right & $8.80^{\mathrm{a}}$ & 3.11 & $10.60^{a}$ & 2.86 & $0.369 \mathrm{~ns}$ \\
\hline & Left & $9.80^{\mathrm{a}}$ & 3.85 & $15.10^{\mathrm{a}}$ & 3.56 & $0.054 \mathrm{~ns}$ \\
\hline
\end{tabular}

Mean with different letters in the same row indicate statistically significance difference $*$; significant $(p<0.05) \quad n s ;$ non-significant $(p>0.05)$ 
Table (5) The mean, standard deviation (SD) values of microstrains induced to abutments and ridges during unilateral and bilateral loading in $\mathrm{CoCr}$ (Paired t-test).

\begin{tabular}{|c|c|c|c|c|c|c|}
\hline \multicolumn{6}{|c|}{$\mathrm{CoCr}$} & \multirow{3}{*}{ P-value } \\
\hline \multirow{2}{*}{ Side } & \multirow{2}{*}{$\begin{array}{c}\text { Material } \\
\text { Site }\end{array}$} & \multicolumn{2}{|c|}{ Implant (Canine) } & \multicolumn{2}{|c|}{ Ridge (Molar) } & \\
\hline & & Mean & SD & Mean & SD & \\
\hline \multirow{2}{*}{ Unilateral } & Right & $34.30^{\mathrm{a}}$ & 3.81 & $10.40^{\mathrm{b}}$ & 3.21 & $\leq 0.001 *$ \\
\hline & Left & $306.82^{\mathrm{a}}$ & 16.47 & $14.60^{\mathrm{b}}$ & 4.16 & $\leq 0.001 *$ \\
\hline \multirow{2}{*}{ Bilateral } & Right & $298.60^{\mathrm{a}}$ & 18.09 & $14.00^{\mathrm{b}}$ & 2.77 & $\leq 0.001 *$ \\
\hline & Left & $380.00^{\mathrm{a}}$ & 16.22 & $19.40^{\mathrm{b}}$ & 4.15 & $\leq 0.001 *$ \\
\hline
\end{tabular}

Mean with different letters in the same row indicate statistically significance difference

*; significant $(p<0.05) \quad n s ;$ non-significant $(p>0.05)$

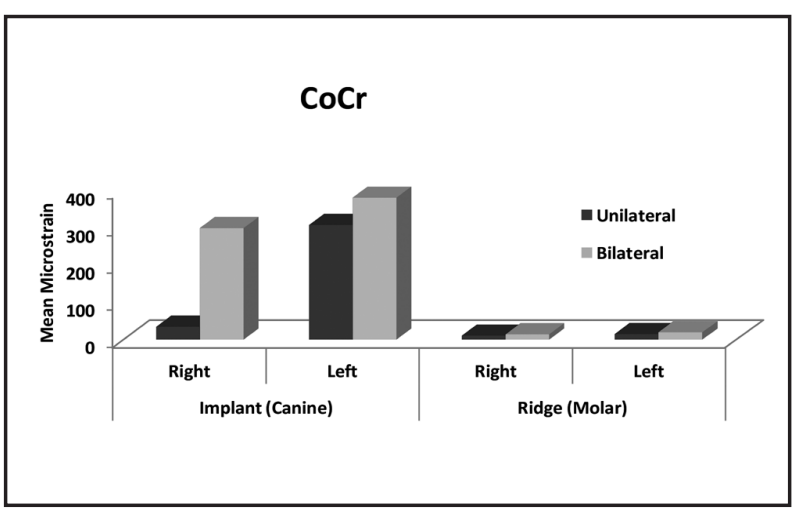

Fig. (9) Bar chart representing microstrains measured with Unilateral and Bilateral load application in PEEK.

\section{DISCUSSION}

The results obtained from this study showed that in all loading situations whether unilateral or bilateral, the use of straight cobalt chromium bar, and the use of straight polyetheretherketone bar reduce the strains delivered to the supporting alveolar bone under the denture base. The stress concentration on the implants abutment using cobalt chromium bar is in agreement with previous clinical and mechanical studies which observed increasing in stress concentration on the implant abutments ${ }^{(\mathbf{1 4})}$

Dental implants are subjected to mechanical forces because of the loading placed on the

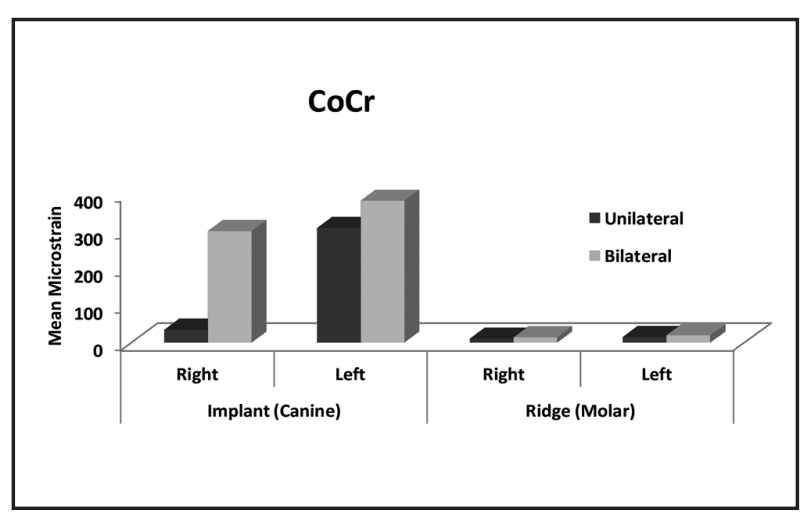

Fig. (9) Bar chart representing microstrains induced to abutments and ridges during unilateral and bilateral loading in $\mathrm{CoCr}$

prosthesis. Forces are described as compressive, tensile, and shear. Compressive forces tend to maintain the integrity of an implant. In general, the implant supported overdentures best accommodate compressive forces, where as shear and tensile forces tend to distract or disrupt an implant interface. Stress and strain may be applied to the bone surrounding the implant. As a result, the decrease in trabeculation of bone that occurs after tooth extraction is reversed. Bone trabeculae and density increase when the dental implant is inserted and functioning ${ }^{(15)}$.

This stress shift from the ridge to the implant supporting structures might be beneficial for stress 
reduction in cases with severely resorped ridges and to decrease the liability of prosthetic complications in patients presented with compromised ridges ${ }^{(16)}$.

PEEK is used in medicinal products, in order to achieve greater benefits: in order to make a product lighter, have a higher level of design freedom and a higher level of functional integration on the one hand, but also as a cheaper alternative to precious metal or other materials, on the other hand. Its performance characteristics include biocompatibility, chemical stability, resistance to gamma and X-ray radiation and radiological transparency ${ }^{(17)}$.

The results obtained from this study showed that the use of polyetheretherketone straight bar caused favorable load distribution to the alveolar ridge, and shifting the stresses to the implant supporting structures. Due to its insolubility in water and low reactivity with other materials, peek could be suitable for patients allergic to $\mathrm{Cr}-\mathrm{Co}$, or sensitive to the metallic taste of conventional Cr-Co. Another important advantage of this type of restoration is that it could be easily relined. Due to a $4 \mathrm{GPa}$ modulus of elasticity, it is as elastic as bone and can reduce stresses transferred to the abutment teeth. Furthermore, the white color of BioHPP frameworks provides a different esthetic approach than the conventional metal framework display does. Additional advantages of this polymer material are elimination of allergic reactions and metallic taste, high polishing qualities, low plaque affinity, and good wear resistance ${ }^{(18)}$.

From this study supports this suggestion, use of polyetheretherketone straight bar may satisfy the increased demand for retention and alveolar ridge protection providing a more economic treatment approach for patients with compromised ridges. And it was documented that there was significant increase in the amount of strains transmitted to the implant supporting structures and alveolar ridge with two bar materials with unilateral loading. Bilateral loading most probably allow occlusal stability and broad load distribution that preserve the overdenture supporting structures.

\section{CONCLUSIONS}

\section{From the results of this study it could be con- cluded that:}

1. In all loading situations whether unilateral or bilateral, significantly greater amount of stresses are transmitted to the implants.

2. Under bilateral and unilateral loading the use of polyetheretherketone straight bars transmits less amount of stresses to the residual ridge.

3. Unilateral loading is more traumatic to the implants and residual ridge compared to bilateral loading for different bars.

\section{REFERENCES}

1. The glossary of prosthodontic terms (GPT 8). 2005. p. 49.

2. Rissin L, House J, Manly R, Kapur K.: Clinical comparison of the masticatory performance and electromyographic activity of patients with complete dentures, overdentures, and natural teeth. J Prosthet Dent .1978; 39: 50811.

3. Crum R, Rooney G.: Alveolar bone loss in overdentures; a 5year study. J Prosthet Dent .1978; 40 :6103.

4. Feine J, Carlsson G, Awad M, Chehade A, Duncan W.: The McGill consensus statement on overdentures. Mandibular two-implant overdentures as first choice standard of care for edentulous patients. Gerodontolog. 2002; 3: 19-4.

5. Thomason J, Kelly S, Bendkowski A, Ellis J.: Two implant retained overdentures-a review of the literature supporting theMcGill and York consensus statements. J Dent 2012; 40: 22-34.

6. Stoumpis C, Kohal R.: To splint or not to splint oral implants in the implant-supported overdenture therapy? A systematic literature review. J Oral Rehabil. 2011; 38: 857-69.

7. Takeshita S, Kanazawa M, Minakuchi S.: Stress analysis of mandibular two-implant overdenture with different attachment systems. Dent Mater J .2011; 30: 928-34.

8. Spazzin A, Dos Santos M, Sobrinho L, Consani R, Mesquita M.: Effects of horizontal misfit and bar framework material on the stress distribution of an overdenture-retaining bar system: a 3D finite element analysis. J Prosthodont. 2011; 20:517-22.

9. Clelland N, Gilat A, Mc Gumphy, EA, Brantley W.: A photoelastic and strain gauge analysis of angled abutments for implant system. Int $\mathrm{J}$ Oral Maxillofac Implants. 1993; 8:54-60. 
10. Koutouzis T, Richardson J, Lundgren T.: Comparative soft and hard tissue responses to titanium and polymer healing abutments. J. Oral Implantol.2011; 37, 174-182.

11. Bayer S, Komor N, Kramer A, Albrecht D, Mericske R.: Retention force of plastic clips on implant bars: A randomized controlled trial. Clin. Oral Implants Res.2012; $23,1377-1384$.

12. Schwitalla A. Muller W.: PEEK dental implants: A review of the literature. J. Oral Implantol. 2013; 39, 743-749.

13. Stawarczyk B, Beuer F, Wimmer T, Jahn D, Sener B, Roos M $\therefore$ Polyetheretherketone-a suitable material for fixed dental prostheses? J. Biomed. Mater. Res. B Appl . Biomater.2013; 101, 1209-1216.
14. Mensor M.: Classification and selection of attachements. J Prosthet Dent. 1973; 20:494- 494 .

15. Zarb G, Schmitt A.: Edentulous predicament. I. A prospective study of the effectiveness of implant supported fixed prostheses, J Am Dent Assoc.1996;127:59-72.

16. Misch C.: Dental implant prosthetics. Elsevier Mosby CO., St Louis Missouri 2005.

17. Green Stuart DR.: Using Implantable-Grade PEEK for In Vivo Devices. MDDI. May 1, 2005

18. Kistler F, Adler S, Kistler S.: PEEK-Hochleistung skunststoffeim implant at-prothetischen Workflow. Implantologie J 2013;7: 17-42. 